San Jose State University

SJSU ScholarWorks

Faculty Publications

School of Global Innovation and Leadership

$7-9-2020$

\title{
To share or not to share: the optimal advertising effort with asymmetric advertising effectiveness
}

\author{
Qingying Li \\ Donghua University \\ Hao Ding \\ Donghua University \\ Tianqin Shi \\ San Jose State University, tianqin.shi@sjsu.edu \\ Yanli Tang \\ Sun Yat-sen University
}

Follow this and additional works at: https://scholarworks.sjsu.edu/sgil_pub

Part of the Advertising and Promotion Management Commons, and the Marketing Commons

\section{Recommended Citation}

Qingying Li, Hao Ding, Tianqin Shi, and Yanli Tang. "To share or not to share: the optimal advertising effort with asymmetric advertising effectiveness" Annals of Operations Research (2020). https://doi.org/ $10.1007 /$ s10479-020-03711-8

This Article is brought to you for free and open access by the School of Global Innovation and Leadership at SJSU ScholarWorks. It has been accepted for inclusion in Faculty Publications by an authorized administrator of SJSU ScholarWorks. For more information, please contact scholarworks@sjsu.edu. 


\title{
To Share or Not to Share: The Optimal Advertising Effort with Asymmetric Advertising Effectiveness
}

\author{
Qingying Li \\ liqingying@dhu.edu.cn \\ Glorious Sun School of Business and Management, Donghua University, Shanghai, China \\ Hao Ding \\ welltim@,foxmail.com \\ Glorious Sun School of Business and Management, Donghua University, Shanghai, China \\ Tianqin Shi \\ tianqin.shi@sjsu.edu \\ Lucas College and Graduate School of Business, San José State University, San Jose, USA \\ Yanli Tang \\ yanli.tang@,connect.polyu.hk \\ Lingnan College, Sun Yat-sen University, Guangzhou, 510275, China
}

June 5,2020 


\begin{abstract}
In this paper, we study a two-stage model in which a manufacturer expands to a new market through a local retailer and has private information on the advertising effectiveness. The manufacturer chooses the information sharing format with the retailer, either no information sharing or mandatory information sharing. Under no information sharing format, the manufacturer and the retailer play a signaling game. We derive both separating and pooling equilibria and conduct equilibrium refinements for the signaling game. Under mandatory information sharing format, the manufacturer simply informs the retailer the advertising effectiveness. We also establish the stylized model and derive the optimal advertising effort. By comparing the manufacturer's ex ante profit under the two information sharing formats, we find that the manufacturer always prefers mandatory information sharing, under which both the advertising effort and profit can be higher. We also observe that unlike the common case that the channel members may have different preference over the information sharing formats, the manufacturer and the retailer can actually achieve alignment. While some previous studies suggest that the manufacturer and the retailer may have different preference over the information sharing formats, we find that they can actually achieve alignment with asymmetric information on advertising effectiveness.
\end{abstract}

Keywords: advertising effectiveness, signaling game, asymmetric information, information sharing 


\section{Introduction}

World merchandise exports have almost doubled from about US\$10 trillion in 2005 to US\$ 19.67 trillion in 2018 (WTO 2019, UNCTAD 2019). With the significant growth in global trade and an increasing number of affluent consumers in developing countries, expanding and conducting business globally has become essential to many businesses. When entering new markets overseas, companies usually seek partnership with local distributors in order to minimize cost and risk, meet local regulatory requirements, and benefit from local distributors' unique expertise of their own markets (Arnold 2000). Manufacturers often attempt to directly influence consumers' purchase decisions through the use of advertising to overcome differing objectives between the retailers and themselves (Lal and Narasimhan 1996) and to achieve noteworthy brand successes (Interbrand 2019). For example, Procter \& Gamble (P\&G) began its advertising campaigns almost two years before entering China's market (Riley 2013).

Meanwhile, large brand-owning manufacturers such as P\&G, Unilever, and CocaCola, regularly conduct market research on demand and consumer preferences (Jiang et al. 2016). For instance, in order to open the Russian market, $P \& G$ collaborated with St. Petersburg University to gain a comprehensive understanding of the local market and develop its advanced distribution system (Pepper 2012). Also, manufacturers can have exclusive sales and predication experience in their home country. As a result, it is not necessarily true that downstream retailers are better informed of market information than upstream manufacturers, especially when products are introduced to a new market. In fact, manufacturers can have better information about the factors that affect sales of their own products (Gal-Or et al. 2008) as well as advertising effectiveness (Desai 2000). Without such private information, retailers may react in a way that results in suboptimal pricing and losing sales. Such supply chains operate in environments characterized by escalating levels of information asymmetry in terms of demand, quality and cost (Bakshi 2015, Li et al. 2017, Chod et al. 2019). However, very few studies have looked into information asymmetry on advertising effectiveness in an emerging supply chain.

One remedy for this problem is information sharing between manufacturers and retailers, as extensively reviewed in Chen (2003). Manufacturers can commit to sharing 
advertising information with the retailer. When such mandatory information sharing is absent or perceived as unreliable by retailers, manufacturers can also signal favorable information to their retailers by increasing wholesale price and/or advertising expenditure (Chu 1992, Desai 2000, Ebrahim-Khanjari 2012, Guo and Jiang 2016). Thus, in this research, we ask the following questions: Shall the manufacturer voluntarily and explicitly share its advertising effectiveness information with the retailer? Moreover, if the manufacturer does choose no information sharing, then what should be the manufacturer's optimal signaling strategy? Regardless, what would be the optimal wholesale price and advertising effort for the manufacturer?

To answer these questions, we consider a two-stage model for a manufacturer expanding to a new market. The manufacturer will conduct advertising in the new market and sell through a local retailer. Before entering the new market, the manufacturer chooses an information sharing format and a wholesale price. After expanding to the new market, the manufacturer can obtain private information about advertising effectiveness by conducting investigations. The manufacturer then determines the advertising effort under the pre-determined information sharing format. Under no information sharing format, we study the signaling game between the manufacturer and the retailer. We derive both pooling and separating equilibria on the advertising effort and the conditions for their existences. We also conduct the equilibrium refinement to derive the unique lexicographically maximum sequential equilibrium. Under mandatory information sharing format, we solve the stylized game model. We then investigate the manufacturer's profit to determine the ex ante optimal wholesale price under each information sharing format.

By comparing the manufacturer's ex ante optimal profit under the two information sharing formats, we find that the manufacturer always prefers the mandatory information sharing. Previous literature indicates that when the manufacturer has private information, the retailer prefers no information sharing because the manufacturer's downward distortion in the wholesale price endows the retailer a higher profit margin. However, in our model, the private information is signaled through the advertising effort, in which case the distortion also affects the market demand. Thus, 
the retailer may also prefer mandatory information sharing, which signifies that the two supply chain members can achieve alignment regarding the information sharing format. We also find that the manufacturer's advertising effort under no information sharing format is no greater than that under mandatory information sharing format.

Subsequent sections are organized as follows. We review related literature in Section 2. Section 3 provides the basic modeling framework and characterizes the conditionally optimal advertising efforts and retail price. We then investigate the manufacturer's optimal strategy under no information in Section 4 and that under mandatory information sharing in Section 5. Section 5 also compares the two information sharing formats. Section 6 concludes our paper with a summary of our findings, implications, and limitations.

\section{Literature Review}

Our research is related to two streams of literature: signaling under information asymmetry, and supply chain management with advertising effort.

Signaling is a type of a dynamic Bayesian game that applies principle-agent theory, and it arises when one player who owns private information takes effort to credibly reveal the information to the player who lacks information. The most common private information is market demand because a down-stream supply chain member, which is closer to the market, is better informed of demand information than its upstream partner. For example, Li et al. (2014) investigate supplier encroachment into a retailer's market where the retailer owns private information of market size and signals through order quantities. They show that such information asymmetry will magnify double marginalization. The supplier encroachment under information asymmetry is further explored by considering risk attitude (by Li et al. 2017), production cost reduction (Sun et al. 2019), and product quality (Zhang et al. 2019). Anand and Goyal (2009) consider a supplier trading with two retailers, where one is an informed incumbent and the other is an uninformed entrant. The incumbent, if acquires information, can then signal to the supplier through order quantities, and the supplier then decides whether to leak the information to the uninformed entrant. They show that because of the potential 
information leakage by the supplier, the incumbent may prefer not to acquire information even if it is costless. Yan et al. (2017) also investigate a model with one supplier and two retailers with asymmetric information. Four sourcing strategies corresponding to different moving sequences are investigated. They show that the asymmetric retailers have misaligned preferences over the moving sequences. Li and Zhou (2019) consider a horizontal supply chain with an integrated device manufacturer that can source from a foundry or make its own production, where the demand distribution is private information to the former. The capacity reservation equilibrium decisions are derived and analyzed.

Besides market information, some studies also investigate signaling other types of information. Bakshi et al. (2015) consider the case where the vendor has superior knowledge of the product's reliability, and such information is signaled through the vendor's after-sales service contracts. Guo and Jiang (2016) examine the impact of consumers' inequity aversion on a firm's pricing and quality decisions when the firm can signal information of cost efficiency to its consumers through both price and quality. Jiang and Yang (2018) consider a two-period setting in which a firm signals private information of cost and quality to early consumers through prices and later customers can learn the product-quality information from the early customers. Chod et al. (2019) consider a model in which the buyer has private information about its product quality and suppliers face the risk of buyer default. Some studies also investigate the information disclosure/acquisition/updating decisions, selling strategy choices under asymmetric information settings; see, e.g., Dong et al. (2018), Li et al. (2018), Zhao and Li (2018), Lai et al. (2019), Shen et al. (2019a, 2019b), Shi and Shen (2019). In this work, we consider the case in which the manufacturer owns private information about advertising effectiveness, where advertising effectiveness is defined as the effect of advertising effort on product demand.

This research is also related to the studies on advertising efforts in a supply chain setting. In this stream of literature, dynamic models are commonly adopted to investigate the effect of advertising. For example, Xie and Wei (2009) consider cooperative advertising by a retailer who advertises locally and a manufacturer who not 
only advertises nationally but also pays a portion of the retailer's local advertising cost. By deriving the equilibrium pricing and advertising decisions under non-cooperative and cooperative models, they demonstrated that cooperative advertising increases overall advertising efforts by all channel members and reduces retailer prices. Zhang et al. (2013) extend Xie and Wei's (2009) model by considering the effects of advertising on consumers' goodwill and reference prices. Gou et al. (2014) investigate the model in which advertising efforts can improve the firm's goodwill and the market demand is jointed determined by goodwill and advertising effort. Nair and Narasimhan (2006) consider a dynamic model in which a firm's goodwill is enabled by both advertising and quality efforts. They show that the advertising effort rate decreases in goodwill levels while quality effort rate increases in goodwill levels. Lu et al. (2016) study a joint pricing and advertising problem in which sales price and advertising effort can positively affect consumers' reference price and hence demand. They concluded that dynamic pricing and dynamic advertising strategies are strategic complements and dominate the static strategy. Additionally, the length of the sales period plays a key role in determining the superiority of the two dynamic strategies. Specifically, a relatively short sales period highlights the value of the dynamic advertising while a long sales period strengthens the function of dynamic pricing. In this study, we also investigate the decisions on the advertising effort but in a static setting. In addition, different from previous studies, we assume that advertising effectiveness is the manufacturer's private information, and we derive the manufacturer's advertising effort equilibrium to signal the advertising effectiveness to the retailer. Other studies regarding advertising include Shen et al. (2019c), Chiu et al. (2018).

Our research is most closely related to Desai (2000) and Jiang et al. (2016). Desai (2000) considers a supply chain in which a manufacturer intends to expand to the new market through a retailer. The manufacturer has multiple private information about demand and advertising effectiveness, and demand information is signaled via three decision variables, namely wholesale prices, advertising costs, and slotting allowances. While using the same channel structure as, we differentiate our paper from Desai (2000) by obtaining both separating and pooling equilibria under one-dimensional private 
information on the advertising effectiveness and by investigating the manufacturer's ex ante preference over information sharing formats.

Channel members' preference over three information sharing formats (no sharing, mandatory sharing, and voluntary sharing) has been discussed in Jiang et al. (2016). They show that the manufacturer prefers no-sharing format and the retailer prefers mandatory sharing. The impact of demand forecast accuracy and the risk attitude on information-sharing preferences is also investigated. In this work, we examine both mandatory information sharing and no information sharing. Our work differs from Jiang et al.'s (2016) by considering the manufacturer's advertising effort, in which the advertising effectiveness is the private information of the manufacturer and also indirectly affects the market demand. We show that, unlike the results in Jiang et al. (2016), the manufacturer and the retailer can achieve ex ante preference alignment.

\section{Model}

Consider a supply chain consisting of one manufacturer (she) and one retailer (he), where the manufacturer is the brand owner and wants to expand into a new market by selling through the retailer. The manufacturer will take the effort to advertise her products. Advertising is assumed to have a positive effect on the market demand (see,

for example, Gou et al. 2014, Desai 2000), and this effect on demand by a unit of advertising effort is defined as advertising effectiveness. We let $e$ be the advertising effort and $\beta$ be the advertising effectiveness. The advertising effectiveness can be either high or low. Since the manufacturer undertakes the advertising expenditure, the advertising effectiveness is her private information. Follow the common assumption in signaling games (Anand and Goyal 2009, Jiang et al. 2014, 2016, Li et al. 2017, Zhang et al. 2019), we adopt a two-pint distribution to characterize the information asymmetry. Specifically, $\beta$ can be either a high value $\beta_{h}$ with an ex ante probability of $\alpha$ or a low value $\beta_{l}$ with an ex ante probability of $1-\alpha$, where $\beta_{h}>\beta_{l}>0$ and $0 \leq \alpha \leq$ 1. As discussed in the introduction section, we consider the case in which the brandowning manufacturer expands to the new market through the retailer, and only the manufacturer has private information about the advertising effectiveness. The 
manufacturer knows the exact value of advertising effectiveness $\beta$ but the retailer only knows the prior distribution of $\beta$. For ease of presentation, we denote $\theta=\beta_{h} / \beta_{l}$, which characterizes the uncertainty of advertising effectiveness. A larger $\theta$ indicates a higher uncertainty level of advertising effectiveness.

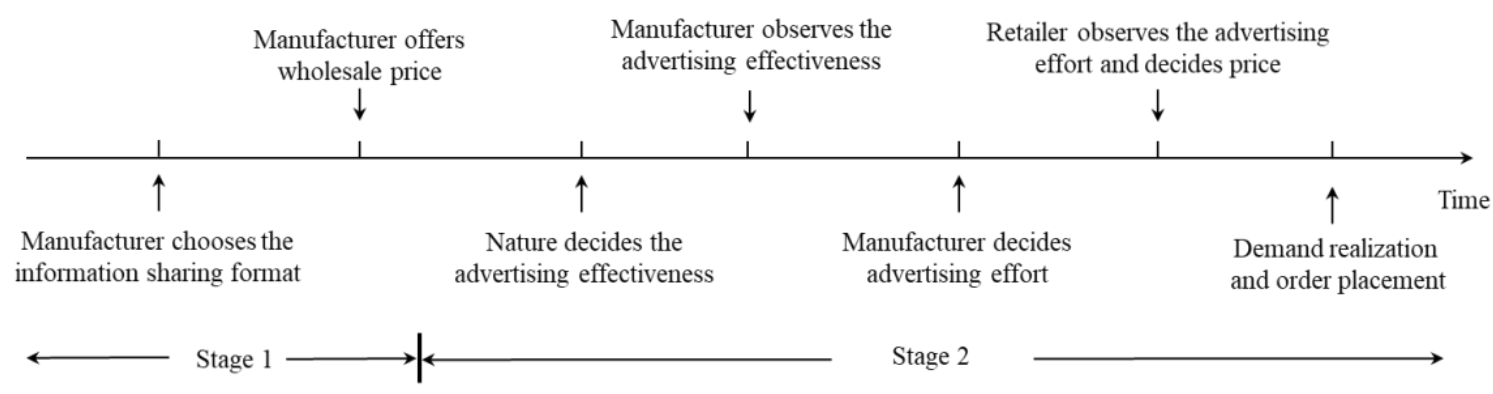

Figure 1. Event sequence

The event sequence is shown in Figure 1. Stage 1 is the pre-entry stage, where the manufacturer first announces the information sharing format to the retailer. As discussed in Jiang et al. (2016), we consider two information sharing formats: no information sharing and mandatory information sharing. Under the no information sharing format, the manufacturer ex ante commits not sharing any advertising effectiveness information with the retailer, and under the mandatory information sharing format, the manufacturer ex ante commits to sharing the true advertising effectiveness information with the retailer. Besides the above two information sharing formats, Jiang et al. (2016) also discuss voluntary information sharing, where the manufacturer ex post decides whether to share the information after receiving it. As in Jiang et al.'s (2016) risk-natural case, the l-type manufacturer wants the retailer to know its type (see the first paragraph of Section 4.1.1 for details) and thus chooses to share information, and the $h$-type manufacturer wants to hide its identity and thus chooses not to share information. The retailer is also aware of it, so that in either case the retailer can correctly infer the manufacturer type. The $h$-type manufacturer is then indifferent between sharing or not sharing. Thus, the voluntary information sharing will lead to the same results as mandatory information sharing. Therefore, this paper focuses on no information sharing and mandatory information sharing. For a given information sharing format, the manufacturer then determines the wholesale price $w$. Note that it 
usually takes time for the manufacturer to conduct advertising before entering the new market and that the manufacturer expands to the new market with well-developed products. We assume the wholesale price is determined in Stage 1.

Then, the manufacturer enters the new market in Stage 2. At the beginning of stage 2 , the nature chooses advertising effectiveness, $\beta_{i}$, where $i=h, l$. The manufacturer observes advertising effectiveness and determines the advertising effort $e$. The retailer observes the advertising effort $e$, formulates his belief on the advertising effectiveness type, say $\beta_{j}$, where $j=h, l$, and chooses the retailing price $p$. Note that the retailer's belief may or may not be consistent with the true value. We assume the advertising effort by the manufacturer is observable to the retailer because the retailer can infer advertising effort from, for example, the publication frequency of videos and posters in social media after the manufacturer conducts advertising.

The market demand is then realized. We assume that the market demand is

$$
D=a-b p+\beta_{i} e,
$$

where $a$ is the potential market size, $b$ is the price-sensitive parameter, and $\beta_{i}$ is the true advertising effectiveness. This demand function is widely used in the existing literature (see, for example, Dong et al. 2016, and Li 2018, Dong et al. 2019, Shi et al. 2020). We assume that the retailer places an order after demand realization so that there is no demand uncertainty. We also assume that the advertisement with an advertising effort $e$ costs the manufacturer $k e^{2}$, where $k>0$. The quadratic advertising cost is also adopted by Zhang et al. (2013) and Lu et al. (2016). To rule out the trivial case that the manufacturer chooses an infinity advertising effort level, we assume that $k>$ $\beta_{L}{ }^{2}\left(\alpha \theta^{2}+1-\alpha\right) / 8 b$. Without loss of generality, we normalize the unit production cost of the product to be zero.

To solve this problem, we use backward induction. Given that the retailer's belief on advertising effectiveness is $\beta_{j}$, he believes that the market demand would be $a-$ $b p+\beta_{j} e$. Suppose $w$ is the wholesale price per unit. The retailer determines the retailing price by maximizing $(p-w)\left(a-b p+\beta_{j} e\right)$, which induces his optimal retailing price $p_{j}(e ; w)=\frac{a+\beta_{j} e+b w}{2 b}$. Expecting the optimal retailing price $p_{j}(e ; w)$ 
as a function of $\beta_{j}$ and being aware of the true advertising effectiveness $\beta_{i}$, the manufacturer's profit, denote as $\Pi_{i j}^{M}(e ; w)$, can be written as

$$
\Pi_{i j}^{M}(e ; w)=w\left(a-b p_{j}(e ; w)+\beta_{i} e\right)-k e^{2}=w\left[\frac{a-b w}{2}+\left(\beta_{i}-\frac{\beta_{j}}{2}\right) e\right]-k e^{2} .
$$

Hereafter, similar to the notation of $\Pi_{i j}^{M}(e ; w)$, we use the first subscript " $i$ " to refer to the true advertising effectiveness (i.e., $\beta_{i}$ ) and the second subscript " $j$ " to refer to the retailer's belief (i.e., $\beta_{j}$ ). We will also use superscripts " $M$ " and " $R$ " to denote the manufacturer and the retailer, respectively.

The manufacturer determines the advertising effort $e$ by maximizing her profit $\Pi_{i j}^{M}(e ; w)$ given by (1). Recall that the retailer's best response retailing price is $p_{j}(e ; w)=\frac{a+\beta_{j} e+b w}{2 b}$. We obtain the following proposition regarding the supply chain's conditionally optimal decisions and outcomes for any given $w, \beta_{i}$ and $\beta_{j}$.

Proposition 1. Suppose that the true advertising effectiveness is $\beta_{i}$, and the retailer's belief is $\beta_{j}$. Given a wholesale price $w$, the manufacturer's optimal advertising effort is $e_{i j}(w)=\frac{\left(2 \beta_{i}-\beta_{j}\right) w}{4 k}$, the retailer's optimal price is $p_{j}(w)=\frac{4 k(a+b w)+\left(2 \beta_{i}-\beta_{j}\right) \beta_{j} w}{8 k b}$, and the manufacturer and the retailer's profits are

$$
\Pi_{i j}^{M}(w)=\frac{(a-b w) w}{2}+\frac{\left(2 \beta_{i}-\beta_{j}\right)^{2} w^{2}}{16 k},
$$

and

$$
\Pi_{i j}^{R}(w)=\frac{1}{64 k^{2}}\left[4 k(a-b w)+\left(2 \beta_{i}-\beta_{j}\right) \beta_{j} w\right]\left[4 k(a-b w)+\left(2 \beta_{i}-\beta_{j}\right)\left(2 \beta_{i}+\beta_{j}\right) w\right],
$$

respectively.

Proposition 1 determines the conditionally optimal advertising effort and retail price for any given wholesale price. In the following sections, we complete the determination of the equilibria. Recall that the manufacturer chooses from two possible information sharing formats at the beginning of stage 1 . For each information format, we first use backward analysis to derive the retailer's optimal price, the manufacturer's equilibrium advertising effort, and the wholesale price decisions. Then, we discuss the manufacturer's preference over the two formats. 


\section{No information sharing}

Under no information sharing format, the manufacturer does not share the advertising effectiveness information to the retailer. Recall that the manufacturer determines the advertising effort $e$ after observing the true advertising effectiveness. The advertising effort $e$ will reflect the manufacturer's observed information, and the retailer will use the advertising effort $e$ to update his belief on advertising effectiveness. Since the manufacturer can anticipate the retailer's reaction to her advertising effort $e$, she may purposely distort the advertising effort $e$ to induce the retailer to formulate a belief that can benefit herself. Meanwhile, the retailer is also aware of the likelihood of information distortion. Thus, a signaling game arises between the two supply chain members. In this section, we first analyze the equilibrium of the signaling game between the manufacture and the retailer in Section 4.1, and then we discuss the manufacturer's decision on the wholesale price given the equilibrium in Section 4.2.

\subsection{The signaling game equilibrium}

In a signaling game, two mutually exclusive types of equilibria might arise. The first is a separating equilibrium, where the manufacturer varies her advertising effort decisions based on advertising effectiveness, in which case the retailer can exactly infer the true advertising effectiveness. The second is a pooling equilibrium, where the manufacturer makes the same advertising effort decision no matter what the advertising effectiveness is, in which case the retailer cannot update his belief on the advertising effectiveness. We discuss these two types of equilibria in the following two subsections, respectively.

Recall that the wholesale price $w$ is given when the signaling game arises. Thus, when we analyze the manufacturer's signaling decision on the advertising effort $e$ in this subsection, we omit the parameter $w$ from the notations for ease of presentation.

\subsubsection{Separating}

For any given advertising effort $e$, the manufacturer prefers the retailer to choose a low retailing price so that the realized market demand is high. Recall that if the retailer's belief on the advertising effectiveness is $\beta_{j}$, then his best response optimal price is

$p_{j}(e ; w)=\frac{a+\beta_{j} e+b w}{2 b}$. Recall also that $\beta_{h}>\beta_{l}>0$. Thus, if the manufacturer observes 
a high advertising effectiveness $\beta_{h}$ (hereafter referred to as the " $h$-type manufacturer"), then she has the incentive to mimic that she observes low advertising effectiveness (hereafter referred to as the "l-type manufacturer") so that the retailer can set a low price. On the other hand, the $l$-type manufacturer has the incentive to separate from the $h$-type manufacturer. This can easily verified by the relation that $\Pi_{h l}^{M}(e)>$ $\Pi_{h h}^{M}(e)>\Pi_{l l}^{M}(e)>\Pi_{l h}^{M}(e)$ and $e_{h l}>e_{h h}>e_{l l}>e_{l h}$ from (1). That is, for any given advertising effort $e$, the $h$-type manufacturer can obtain a higher profit by mimicking the $l$-type manufacturer; and the $l$-type manufacturer will lose profit if being perceived as an $h$-type manufacturer. This is also illustrated in Figure 2.

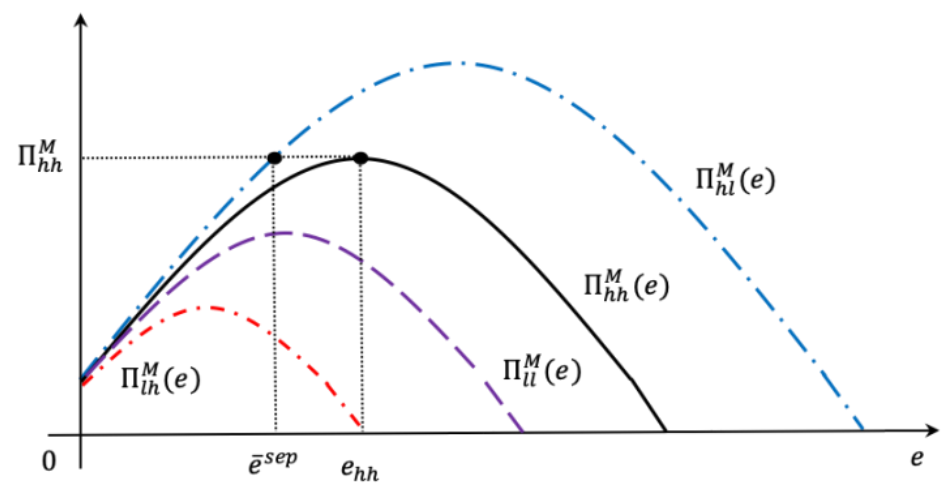

Figure 2. The manufacturer's optimal profit functions

We use $\beta_{j(e)}$ to denote the updated belief of advertising effectiveness by the retailer after observing the manufacturer's advertising effort $e$. It is intuitive that the manufacturer will invest more if the effort is high. Thus, we apply the following belief structure with a threshold on the advertising effort $\hat{e}^{\text {sep }}$,

$$
j(e)= \begin{cases}h, & e>\hat{e}^{\text {sep }}, \\ l, & e \leq \hat{e}^{\text {sep }} .\end{cases}
$$

Under this belief structure, the retailer believes that the advertising effectiveness is low if and only if he observes that the manufacturer's advertising effort is no more than the threshold $\hat{e}^{\text {sep }}$. To separate herself from the $h$-type manufacturer, the $l$-type manufacturer has to distort down his advertising effort to the extent that the $h$-type manufacturer no longer wants to mimic, i.e., it is more profitable for the $h$-type 
manufacturer to set a high advertising effort than mimicking the $l$-type manufacturer's decision. By maximizing the manufacturer's profit subject to the separating condition, we have the following results.

Proposition 2. Under no information sharing, there exists a unique perfect Bayesian separating equilibrium, where an l-type manufacturer chooses

$$
e_{l}^{\text {sep }}=\hat{e}^{\text {sep }}= \begin{cases}\frac{w}{4 k}\left[\left(2 \beta_{h}-\beta_{l}\right)-\sqrt{\left(3 \beta_{h}-\beta_{l}\right)\left(\beta_{h}-\beta_{l}\right)}\right] & 1<\theta \leq 3, \\ \frac{\beta_{l} w}{4 k}, & \theta>3,\end{cases}
$$

and an h-type manufacturer chooses $e_{h}^{\text {sep }}=\frac{\beta_{h} w}{4 k}>\hat{e}^{\text {sep }}$.

Note that $\frac{\beta_{i} w}{4 k}$ is the optimal advertising effort when there is no information asymmetry between the supply chain members. Thus, from Proposition 2, if the advertising effectiveness uncertainty is large enough, i.e., $\theta>3$, then the $l$-type manufacturer can signal the true advertising effectiveness to the retailer without distorting her advertising effort. This is known as costless separating. When the advertising effectiveness uncertainty is not large, i.e., $1<\theta \leq 3$, the $l$-type manufacturer has to distort the advertising effort to convince the retailer that the true advertising effectiveness is low. Specifically, it is easy to show that

$$
\beta_{l}-\left[\left(2 \beta_{h}-\beta_{l}\right)-\sqrt{\left(3 \beta_{h}-\beta_{l}\right)\left(\beta_{h}-\beta_{l}\right)}\right]=\sqrt{\beta_{h}-\beta_{l}} \cdot\left[\sqrt{3 \beta_{h}-\beta_{l}}-\sqrt{4\left(\beta_{h}-\beta_{l}\right)}\right]>0,
$$

where the last inequality holds because $1<\theta \leq 3$ (or, equivalently, $\beta_{l}<\beta_{h} \leq 3 \beta_{l}$ ) implies that $\left(3 \beta_{h}-\beta_{l}\right)>4\left(\beta_{h}-\beta_{l}\right)$. This signifies that if $1<\theta \leq 3$, then the $l$ type manufacturer has to distort down the advertising effort and hence fails to achieve the maximum profit under symmetric information. The $l$-type manufacturer's profit lose due to distorting down the advertising effort is the signaling cost, and this is referred to as costly separating.

\subsubsection{Pooling}

Proposition 2 shows that an $l$-type manufacturer may distort down the advertising effort $e$ and incur a signaling cost to separate herself from an $h$-type manufacturer. When the system parameters are such that the signaling cost is too high, i.e., the downward distortion in the advertising effort is too large, the $l$-type manufacturer may 
give up separating herself from the $h$-type one, but sets a higher advertising effort to pool with the $h$-type manufacturer. The $l$-type manufacturer would prefer pooling if pooling brings her a higher profit than costly separating from an $h$-type manufacturer does. For an $h$-type manufacturer, the benefit of pretending to be an $l$-type is to induce the retailer to set a low price to increase the realized demand, and the cost of mimicking is decreasing in the realized demand due to the lowered advertising effort. If the $l$-type manufacturer's advertising effort is too low, the $h$-type manufacturer will choose her first-best advertising effort to separate herself. The two types of the manufacturer will pool only if pooling can bring them higher profit than separating.

Since the $h$-type manufacturer will separate herself if the advertising effort is too low, we adopt the following pooling belief structure as used in Guo and Jiang (2016) and Sun et al. (2019): There exists a threshold advertising effort $\hat{e}^{\text {pool }}$ such that the retailer's belief on the investment effectiveness is $\beta_{h}$ if he observes an advertising effort $e>\hat{e}^{\text {pool }}$ and the retailer cannot update his belief if $e \leq \hat{e}^{\text {pool }}$. That is,

$$
j(e)= \begin{cases}h, & e>\hat{e}^{\text {pool }}, \\ \text { prior distribution, } & e \leq \hat{e}^{\text {pool }} .\end{cases}
$$

If the two types of manufacturers choose to pool at advertising effort $e$, the retailer cannot update his belief on the advertising effectiveness so that his optimal retailing price is determined by maximizing

$$
\Pi_{i p}^{R}(p, e)=\alpha \Pi_{i h}^{R}(p, e)+(1-\alpha) \Pi_{i l}^{R}(p, e) .
$$

Here, we replace $\Pi_{i j}^{R}$ with $\Pi_{i p}^{R}$ to denote the retailer's belief in the pooling case. One can show that when facing a manufacturer with a pooling strategy, the retailer's optimal retailing price is

$$
p_{p}(e)=\frac{a+\mu e+b w}{2 b} \text {. }
$$

where $\mu=\alpha \beta_{h}+(1-\alpha) \beta_{l}$ is the ex ante expectation on the manufacturer's advertising effectiveness. Then, from (1), the $i$-type manufacturer's profit is

$$
\Pi_{i p}^{M}(e)=w\left(a-b p_{p}(e)+\beta_{i} e\right)-k e^{2}=w\left[\frac{a-b w}{2}+\left(\beta_{i}-\frac{\mu}{2}\right) e\right]-k e^{2} .
$$

To derive the pooling equilibrium, we maximize $i$-type manufacturer's profit subject to the condition that both types of the manufacturer being more profitable when they 
choose pooling than separating. Let $\bar{\theta}(\alpha)=\frac{\alpha^{2}-2 \alpha-3}{\alpha^{2}-4 \alpha-1}$. Proposition 3 thus provides the existence condition for a pooling equilibrium.

Proposition 3. If $1<\theta \leq \bar{\theta}(\alpha)$, then a perfect Bayesian pooling equilibrium exists and the manufacturer will pool with an advertising effort $e^{\text {pool }}=\hat{e}^{p o o l}=\frac{\left(2 \beta_{l}-\mu\right)^{+} w}{4 k}$.

\subsection{3 the LMSE equilibrium}

From Propositions 2 and 3, a separating equilibrium (either costly separating or costless separating) always exists while a pooling equilibrium only exists when $1<\theta \leq \bar{\theta}(\alpha)$. When there are multiple equilibria, we need to conduct the equilibrium refinement. One commonly adopted refinement rule is the intuitive criterion. However, as discussed in Mailath et al. (1993), the intuitive criterion may sometimes rule out pooling due to logical incompleteness, and a lexicographically maximum sequential equilibrium (LMSE) outcome is more plausible. Refining the equilibria by the LMSE concept in signaling games is adopted in many recent works (e.g., Tian and Jiang 2016, Jiang et al. 2016, Guo and Jiang 2016). In this work, we also adopt the LMSE concept, which selects the most profitable outcome for the type that wants to reveal identity. In our model, the $l$-type manufacturer has the incentive to reveal her identity and the $h$-type manufacturer wants to mimic. Thus, the LMSE refinements select the equilibrium that is more profitable for the $l$-type manufacturer; that is, we compare $\Pi_{l l}^{M}\left(e_{l}^{s e p}\right)$ with $\Pi_{l p}^{M}\left(e^{p o o l}\right)$ and choose the larger one.

Let $\overline{\bar{\theta}}(\alpha)=\frac{\alpha^{4}+2 \alpha^{3}+12 \alpha^{2}+14 \alpha-8 \sqrt{\alpha+2 \alpha^{2}+\alpha^{3}}+3}{\alpha^{4}+14 \alpha^{2}+1}$. The unique LMSE is summarized in the following proposition.

Proposition 4. Under no information sharing, a unique LMSE outcome exists. Specifically, the manufacturer will pool if $1<\theta \leq \overline{\bar{\theta}}(\alpha)$ and will separate if $\theta>$ $\overline{\bar{\theta}}(\alpha)$.

Based on Propositions 2, 3 and 4, we depict the manufacturer's LMSE in Figure 3 , where the $x$-axis is the ex ante probability of the $h$-type manufacturer $\alpha$ and the $y$ - 
axis is the uncertainty on the advertising effectiveness $\theta$. Recall that $0 \leq \alpha \leq 1$ and $\theta>1$. The curves $\theta=\bar{\theta}(\alpha)$ and $\theta=\overline{\bar{\theta}}(\alpha)$, and the line $\theta=3$ divide the x-y plane into four parts. If $1<\theta \leq \overline{\bar{\theta}}(\alpha)$, the manufacturer will pool, where both pooling and separating equilibria exist but pooling is more profitable to the $l$-type manufacturer. If $\overline{\bar{\theta}}(\alpha)<\theta \leq 3$, the manufacturer will conduct a costly separating. Specifically, when $\overline{\bar{\theta}}(\alpha)<\theta \leq \bar{\theta}(\alpha)$, pooling equilibrium exists but is not as profitable as the separating equilibrium for the $l$-type manufacturer; and when $\bar{\theta}(\alpha)<\theta \leq 3$, pooling equilibrium no longer exists and separating is the unique equilibrium. If $\theta>3$, the manufacturer attains a costless separating.

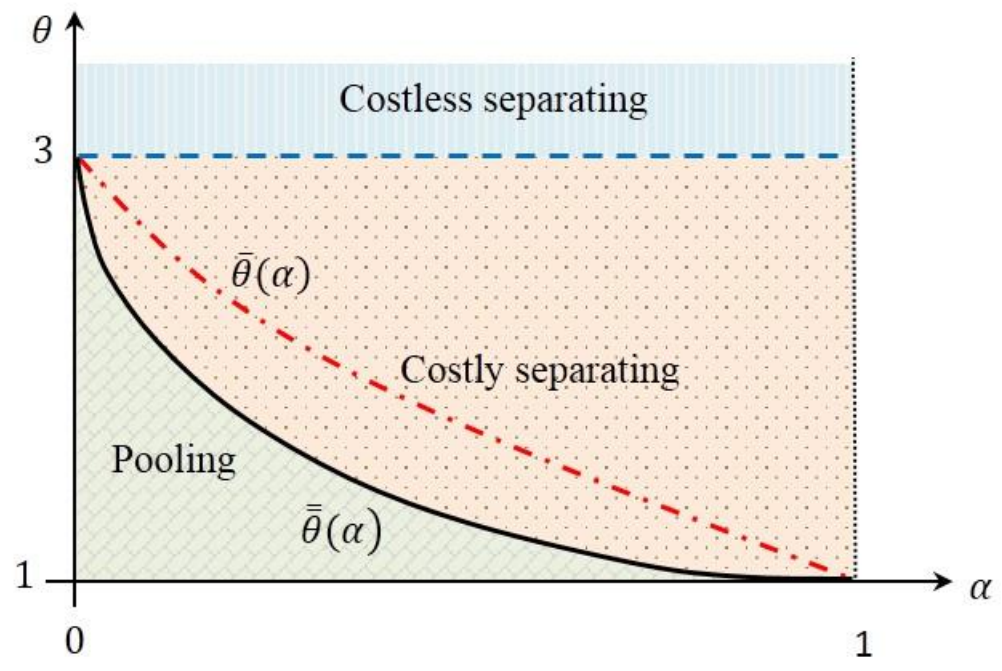

Figure 3. The LMSE under no information sharing.

\subsection{Manufacturer's ex ante wholesale price}

In the previous subsection, we obtain the manufacturer's ex post LMSE to signal advertising effectiveness information. In this subsection, we determine the manufacturer's ex ante wholesale price given the LMSE.

Recall that the manufacturer has different LMSE depending on the relative magnitude of the advertising effectiveness uncertainty level $\theta$ and the prior belief structure $\alpha$, as shown in Figure 3. We, therefore, analyze the manufacturer's ex ante wholesale price according to different values of $\theta$. The manufacturer's expected ex 
ante profit is $E_{i}\left[\Pi_{i j}^{M}(w)\right]$ where the retailer's belief $j$ can either be " $i$ " with separating equilibrium or be " $p$ " with pooling equilibrium, depending on the value of the advertising effectiveness $\theta$. We have the following proposition.

Proposition 5. Under no information sharing, the manufacturer's optimal ex ante wholesale price and optimal ex ante profit are

$$
w= \begin{cases}\frac{4 a k}{8 b k-\beta_{l}^{2}\left[1+2 \alpha(\theta-1)-3 \alpha^{2}(\theta-1)^{2}\right]}, & \text { if } \theta \leq \overline{\bar{\theta}}(\alpha), \\ \frac{4 a k}{8 b k-\beta_{l}^{2} \gamma}, & \text { if } \overline{\bar{\theta}}(\alpha)<\theta \leq 3, \\ \frac{4 a k}{8 b k-\beta_{l}{ }^{2}\left(\alpha \theta^{2}+1-\alpha\right)}, & \text { if } \theta>3,\end{cases}
$$

and

$$
\Pi^{M}= \begin{cases}\frac{a^{2} k}{8 b k-\beta_{l}{ }^{2}\left[1+2 \alpha(-1+\theta)-3 \alpha^{2}(-1+\theta)^{2}\right]}, & \text { if } \theta \leq \overline{\bar{\theta}}(\alpha), \\ \frac{a^{2} k}{8 b k-\beta_{l}^{2} \gamma}, & \text { if } \overline{\bar{\theta}}(\alpha)<\theta \leq 3, \\ \frac{a^{2} k}{8 b k-\beta_{l}^{2}\left(\alpha \theta^{2}+1-\alpha\right)}, & \text { if } \theta>3\end{cases}
$$

respectively, where

$$
\gamma=(8 \alpha-7) \theta^{2}+4(1-\alpha)[3 \theta-1+(\theta-1) \sqrt{(3 \theta-1)(\theta-1)}] .
$$

Proposition 5 shows that the manufacturer's optimal ex ante wholesale price has three possible values, depending on whether the LMSE is costless separating, costly separating, or pooling. We can show that the optimal wholesale price is piece wisely increasing in $\theta$ but not monotonic in general, as shown in the following proposition.

Proposition 6. The optimal ex ante wholesale price increases in $\theta$ over the intervals $(1, \overline{\bar{\theta}}],(\overline{\bar{\theta}}, 3]$, and $[3,+\infty)$, respectively.

Figure 4 depicts the optimal wholesale price in a numerical study. The blue solid curve represents the optimal ex ante wholesale price under asymmetric information. The dash-dotted red curve is the optimal ex ante wholesale price under symmetric information in which case both the manufacturer and the retailer know the advertising effectiveness. As depicted in Figure 4, the optimal wholesale price has jumps where the LMSE changes. In addition, the wholesale price under asymmetric information can be 
either higher or smaller than that under symmetric information.

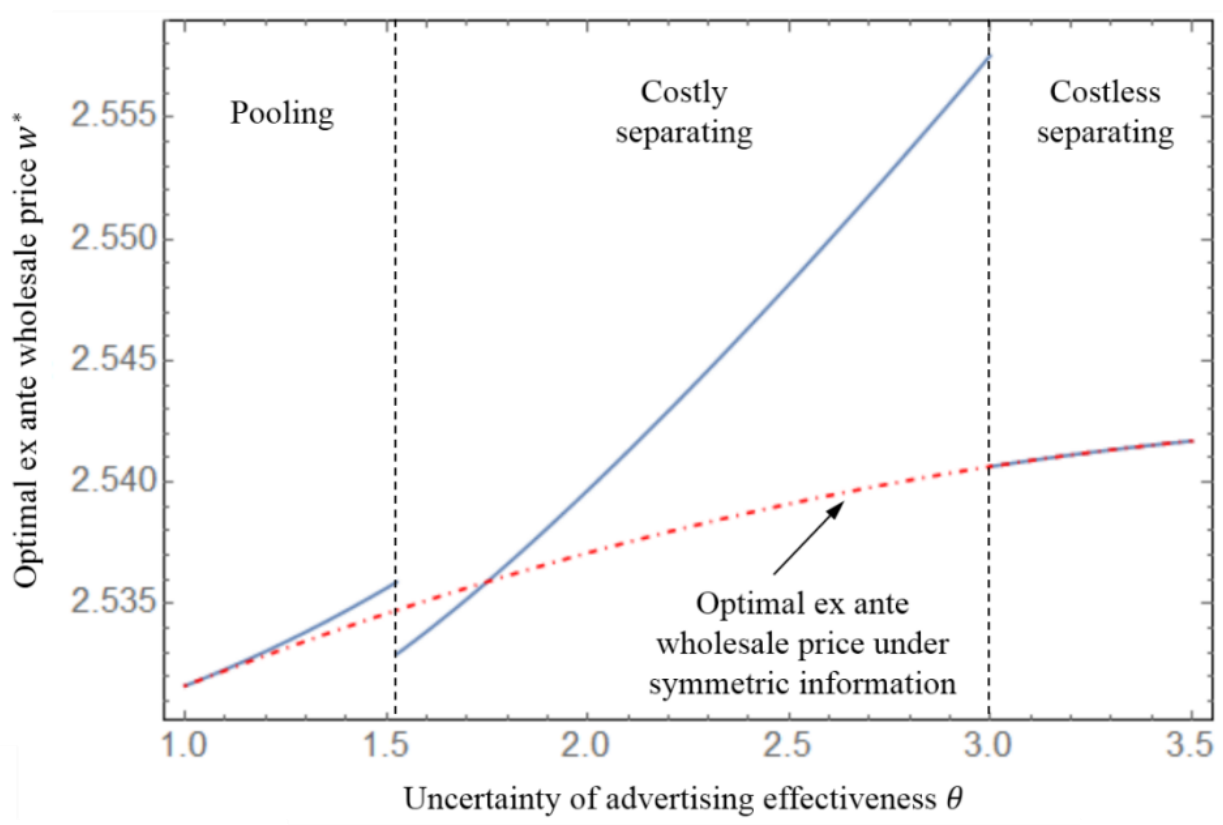

Figure 4 . The optimal wholesale price $(a=100, b=20, \alpha=0.1, k=0.5)$

Given the results in Proposition 5, we can summarize the supply chain members' optimal decisions in Table 1.

Table 1. Optimal advertising effort and retail price under no information sharing

\begin{tabular}{|c|c|c|c|}
\hline$\theta$ & $\beta_{i}$ & $e^{*}$ & $p^{*}$ \\
\hline$\theta \leq \bar{\theta}(\alpha)$ & & $\frac{a \beta_{l}(1+\alpha-\alpha \theta)}{8 b k-\beta_{l}{ }^{2}\left[1+2 \alpha(\theta-1)-3 \alpha^{2}(\theta-1)^{2}\right]}$ & $\frac{a\left\{6 b k+\alpha \beta_{l}{ }^{2}(\theta-1)[\alpha(\theta-1)-1]\right\}}{b\left\{8 b k-\beta_{l}{ }^{2}\left[1+2 \alpha(\theta-1)-3 \alpha^{2}(\theta-1)^{2}\right]\right\}}$ \\
\hline \multirow{2}{*}{$\bar{\theta}(\alpha)<\theta \leq 3$} & $\beta_{h}$ & $\frac{a \beta_{l} \theta}{8 b k-\beta_{l}{ }^{2} \gamma}$ & $\frac{a\left[12 b k+\beta_{l}{ }^{2}\left(\theta^{2}-\gamma\right)\right]}{2 b\left(8 b k-\beta_{l}{ }^{2} \gamma\right)}$ \\
\cline { 2 - 4 } & $\beta_{l}$ & $\frac{a \beta_{l}(2 \theta-1-\sqrt{(\theta-1)(3 \theta-1)})}{8 b k-\beta_{l}{ }^{2} \gamma}$ & $\frac{a\left[12 b k-\beta_{l}{ }^{2}(1+\gamma-2 \theta+\sqrt{(\theta-1)(3 \theta-1)})\right]}{2 b\left(8 b k-\beta_{l}{ }^{2} \gamma\right)}$ \\
\hline \multirow{2}{*}{$\theta>3$} & $\beta_{h}$ & $\frac{a \beta_{l} \theta}{8 b k-\beta_{l}{ }^{2}\left(\alpha \theta^{2}+1-\alpha\right)}$ & $\frac{a\left[12 b k+\beta_{l}{ }^{2}(1-\alpha)\left(\theta^{2}-1\right)\right]}{2 b\left[8 b k-\beta_{l}{ }^{2}\left(\alpha \theta^{2}+1-\alpha\right)\right]}$ \\
\cline { 2 - 4 } & $\beta_{l}$ & $\frac{a \beta_{l}}{8 b k-\beta_{l}{ }^{2}\left(\alpha \theta^{2}+1-\alpha\right)}$ & $\frac{a\left[12 b k-\alpha \beta_{l}{ }^{2}\left(\theta^{2}-1\right)\right]}{2 b\left[8 b k-\beta_{l}{ }^{2}\left(\alpha \theta^{2}+1-\alpha\right)\right]}$ \\
\hline
\end{tabular}

\section{Mandatory Information Sharing and Preference}

In some practical situations, the manufacturer and retailer may develop a more collaborative relationship in which case the manufacturer commits to sharing the 
information with the retailer, and the retailer makes the retailing price decision based on the shared information. This case is known as mandatory information sharing (Jiang et al. 2016). In this section, we consider investigating the supply chain members' optimal decisions under mandatory information sharing in Section 5.1, and we compare the manufacturer's profit under no information sharing and under mandatory information sharing in Section 5.2.

\subsection{Mandatory information sharing}

Under mandatory information sharing, the manufacturer will inform the retailer of the true advertising effectiveness after observing this information. Thus, the retailer's belief is always identical to the true information, i.e., $\beta_{j}=\beta_{i}$. We use a tilde $(\sim)$ over a variable to denote the mandatory information case.

Recall that Proposition 1 derives the optimal decisions when the true information is $\beta_{i}$ and the retailer's belief is $\beta_{j}$ without information sharing. By letting $i=j$, the results reduce to those in the mandatory information sharing case. Thus, we have the following proposition.

Proposition 7. Consider the mandatory information sharing case. Given that the true advertising effectiveness is $i \quad(i=h, l)$ and the wholesale price is $w$, the manufacturer's advertising effort is $\tilde{e}_{i}(w)=\frac{\beta_{i} w}{4 k}$ and the retailer's optimal price is $\tilde{p}_{i}(w)=\frac{4 k(a+b w)+\beta_{i}^{2} w}{8 k b}$. Also, the corresponding profits of the manufacturer and the retailers are $\quad \widetilde{\Pi}_{i}^{M}(w)=\frac{(a-b w) w}{2}+\frac{\beta_{i}^{2} w^{2}}{16 k} \quad$ and $\quad \widetilde{\Pi}_{i}^{R}(w)=$ $\frac{\left[4 k(a-b w)+\beta_{i}^{2} w\right]\left[4 k(a-b w)+3 \beta_{i}^{2} w\right]}{64 k^{2}}$, respectively.

Under mandatory information sharing, the manufacturer's optimal wholesale price can be derived by maximizing $E_{i}\left[\Pi_{i i}^{M}(w)\right]$ because the retailer is always informed with the true advertising effectiveness information. We summarize the results in the following proposition.

Proposition 8. Under mandatory information sharing, the manufacturer's optimal ex 
ante wholesale price and the profit are $\widetilde{w}=\frac{4 a k}{8 b k-\beta_{l}{ }^{2}\left(\alpha \theta^{2}+1-\alpha\right)}$ and $\widetilde{\Pi}^{M}=$ $\frac{a^{2} k}{8 b k-\beta_{l}^{2}\left(\alpha \theta^{2}+1-\alpha\right)}$, respectively.

Notice from the comparison between Propositions 5 and 8 that the manufacturer's optimal ex ante wholesale price and the profit under no information sharing are the same as those under mandatory information sharing, respectively, only when $\theta>3$. In addition, $\widetilde{\mathrm{w}}$ is also the optimal ex ante wholesale price under symmetric information, as depicted in Figure 4.

\subsection{Format preferences}

We have obtained the supply chain members' optimal decisions under both no information sharing and mandatory information sharing. Note that the information sharing format is chosen at the first stage before the manufacturer observes the true information. Therefore, we can compare their ex ante profits to reveal the manufacturer's and the retailer's preference over the two information sharing formats.

Recall that under no information sharing format, the manufacturer's signaling equilibrium depends on $\theta$ and $\alpha$, and thus the manufacturer's ex ante profit has three possible values. Under mandatory information sharing, however, the manufacturer's optimal profit is unique. By comparing the profits under the two information sharing formats, we obtain the following proposition.

Proposition 9. The manufacturer always prefers mandatory information sharing format, i.e., $\widetilde{\Pi}^{M} \geq \Pi^{\mathrm{M}}$.

Proposition 9 shows that the manufacturer's ex ante profit under mandatory information sharing is no less than that under no information sharing. This is because the $l$-type manufacturer under no information sharing has to distort down the advertising effort to signal the information, which causes signaling cost. In Jiang et al. (2016), where the manufacturer signals the market size information through the wholesale price, the manufacturer also prefers mandatory information format because of the signaling cost incurred under no information sharing format.

Jiang et al. (2016) also show that the retailer always prefers no information sharing 
than mandatory information sharing. This is because, under no information sharing format, the manufacturer's distorting down on the wholesale price endows the retailer with a higher marginal profit and thus benefits the retailer. Therefore, the manufacturer and the retailer have misalignment in the information sharing format. However, in our model, we find that the manufacturer and the retailer can achieve alignment. We depict the retailer's ex ante profit $\Pi_{R}$ and $\widetilde{\Pi}^{R}$ in Figure 5 through a numerical study. In this example, the manufacturer chooses to pool when $\theta \leq 1.5$ and achieves costless separating when $\theta \geq 3$. We can see that in this numerical example, the retailer's profit under mandatory information sharing is weakly higher than that under no information sharing. In fact, we obtain $\Pi^{\mathrm{R}} \leq \widetilde{\Pi}^{\mathrm{R}}$ in an extensive numerical study by varying system parameters. However, the complexity of $\widetilde{\Pi}^{R}-\Pi^{R}$ prevents us from establishing the result theoretically.

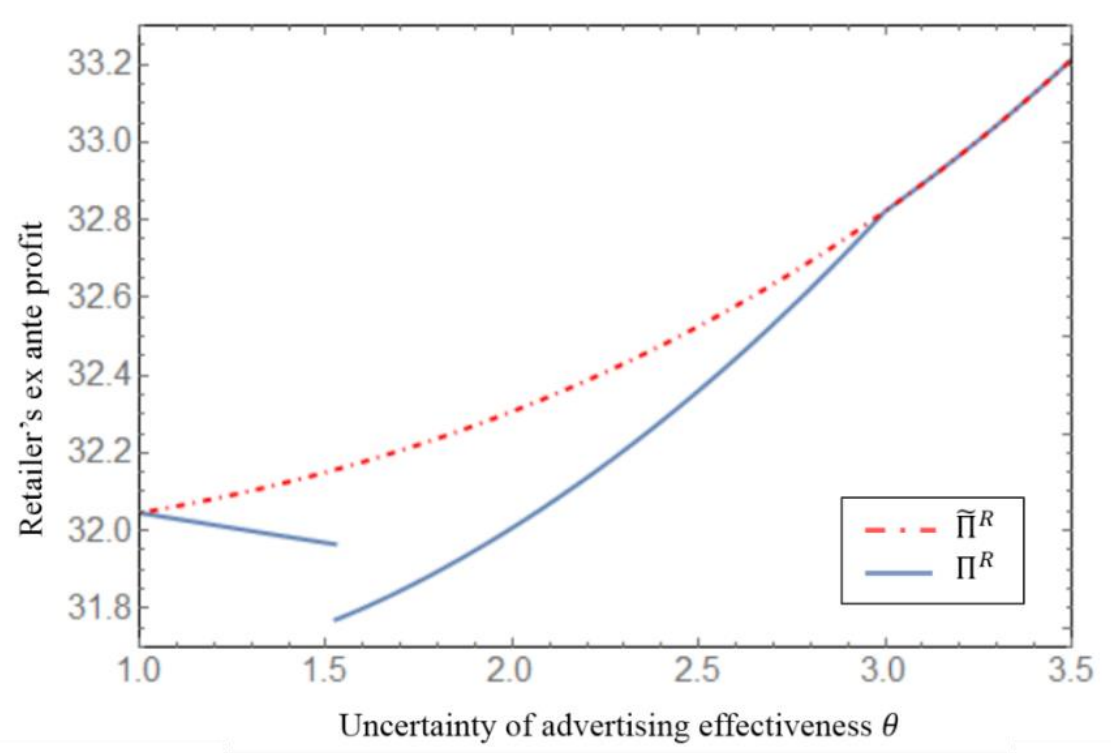

Figure 5. Numerical comparison of $\Pi^{R}$ and $\widetilde{\Pi}^{R}(a=100, b=20, \alpha=0.1, k=0.5)$

The retailer's preference in our model differs from Jiang et al.'s (2016) because the manufacturer signals information through the advertising effort rather than the wholesale price. When the manufacturer distorts down the wholesale price to signal information as in Jiang et al. (2016), the retailer can benefit from the increased profit margin. However, when the manufacturer distorts down the advertising effort to signal 
information as in our case, the retailer will also suffer from the lowered advertising effort because the advertising effort positively correlated with the market demand. Therefore, when the manufacturer signals the advertising effectiveness through the advertising effort, the manufacturer and the retailer can achieve aligned preference over the information sharing format, i.e., mandatory information sharing.

We also compare the advertising efforts under the two information sharing formats and obtain the following proposition.

Proposition 10. The manufacturer will invest less on the advertising effort under no information sharing format than under the mandatory information sharing format; that $i s, e \leq \tilde{e}$.

Proposition 10 shows that the manufacturer tends to invest less when the manufacturer has to signal under no information sharing format than when she ex ante commits to sharing the true information. This is because signal is costly for the manufacturer so that the incentive to take advertising effort decreases.

\section{Conclusion}

In this paper we study a manufacturer's choice of information sharing format with a retailer, where the manufacturer expands to the new market through the retailer and has private information on advertising effectiveness. Under no information sharing format, we investigate both separating and pooling equilibria for the signaling game; and under mandatory information sharing format, we derive the optimal solution through a stylized model. The comparison of the manufacturer's ex ante profit indicates that the manufacturer always prefers mandatory information sharing, which turns out to be consistent with the retailer's preference by a numerical study. We also show that the manufacturer's advertising effort under no information sharing format is no greater than that under the mandatory information sharing format.

In closing, we acknowledge the following limitations of our model. First, we only consider static advertising decisions since we extend the study on advertising effort to an asymmetric information setting. Future research can investigate the asymmetric 
game model with dynamic advertising (e.g., Nair and Narasimhan 2006, Gou 2014) or with a general distribution of information asymmetry (e.g., Li and Zhou 2019, Li and Zhang 2008, Gal-Or et al. 2008). Second, we assume that there is no risk associated with entering the new market. Therefore, considering international business risks such as gray market and buyer default or incorporating supply chain members' risk attitude (e.g., Choi et al. 2016, Ma et al. 2019) can be another possible extension.

\section{Acknowledgement}

This research was supported in part by the National Natural Science Foundation of China under the grant no. 71871052, 71832001, the Fundamental Research Funds for the Central Universities and DHU Distinguished Young Professor Program.

\section{References}

Anand, K. S., \& Goyal, M. (2009). Strategic information management under leakage in a supply chain. Management Science, 55(3), 438-452.

Arnold, D. (2000). Seven rules of international distribution. Harvard Business Review, 78(6), 131-137.

Bakshi, N., Kim, S. H., \& Savva, N. (2015). Signaling new product reliability with after-sales service contracts. Management Science, 61(8), 1812-1829.

Chen, F. (2003). Information sharing and supply chain coordination. Handbooks in operations research and management science, 11, 341-421.

Chiu, C.H., Choi, T.M., Dai, X., Shen, B., Zheng, J. (2018). Optimal Advertising Budget Allocation in Luxury Fashion Markets with Social Influences. Production and Operations Management. 27(8), 1611-1629.

Chod, J., Trichakis, N., \& Tsoukalas, G. (2019). Supplier diversification under buyer risk. Management Science, 65 (7), 2947-3448.

Choi, T. M., Wang, M., \& Yue, X. (2016). Emerging production optimization issues in supply chain systems. Annals of operations research, 240(2), 381-393.

Desai, P. S. (2000). Multiple messages to retain retailers: Signaling new product demand. Marketing Science, 19(4), 381-389.

Dong, C., Liu, Q., \& Shen, B. (2019). To be or not to be green? Strategic investment for green product development in a supply chain. Transportation Research Part E: Logistics and Transportation Review, 131, 193-227. 
Dong, C., Shen, B., Chow, P. S., Yang, L., \& Ng, C. T. (2016). Sustainability investment under cap-and-trade regulation. Annals of Operations Research, 240(2), 509-531.

Dong, C., Yang, Y., \& Zhao, M. (2018). Dynamic selling strategy for a firm under asymmetric information: Direct selling vs. agent selling. International Journal of Production Economics, 204, 204-213.

Ebrahim-Khanjari, N., Hopp, W., \& Iravani, S. M. (2012). Trust and information sharing in supply chains. Production and Operations Management, 21(3), 444-464.

Gal-Or, E., Geylani, T., \& Dukes, A. J. (2008). Information sharing in a channel with partially informed retailers. Marketing Science, 27(4), 642-658.

Guo, X., \& Jiang, B. (2016). Signaling through price and quality to consumers with fairness concerns. Journal of Marketing Research, 53(6), 988-1000.

Gou, Q., Zhang, J., Liang, L., Huang, Z., \& Ashley, A. (2014). Horizontal cooperative programmes and cooperative advertising. International Journal of Production Research, 52(3), 691-712.

Interband. (2019). Best global brands 2019: Iconic moves transforming customer expectations. Available at: https://www.interbrand.com/best-brands/best-global-brands/2019/.

Jiang, B., \& Yang, B. (2018). Quality and pricing decisions in a market with consumer information sharing. Management Science, 65(1), 272-285.

Jiang, B., Tian, L., Xu, Y., \& Zhang, F. (2016). To share or not to share: Demand forecast sharing in a distribution channel. Marketing Science, 35(5), 800-809.

Lai, X., Tao, Y., Wang, F., \& Zou, Z. (2019). Sustainability investment in maritime supply chain with risk behavior and information sharing. International Journal of Production Economics, 218, 16-29.

Lal, R., \& Narasimhan, C. (1996). The inverse relationship between manufacturer and retailer margins: A theory. Marketing Science, 15(2), 132-151.

Li, L., and Zhang, H. (2008). Confidentiality and information sharing in supply chain coordination. Management Science, 54(8), 1467-1481.

Li, G., Zheng, H., Sethi, S. P., \& Guan, X. (2018). Inducing downstream information sharing via manufacturer information acquisition and retailer subsidy. Decision Sciences, forthcoming.

Li, Q. (2018). The optimal multi-period modular design with fairness concerns. International Journal of Production Economics 206, 233-249.

Li, Q., Li, B., Chen, P., \& Hou, P. (2017). Dual-channel supply chain decisions under asymmetric information with a risk-averse retailer. Annals of Operations Research, 257(1-2), 423-447.

Li, Q., \& Zhou, J. (2019). A horizontal capacity reservation game under asymmetric information. International Journal of Production Research, 57(4), 1103-1118. 
Li, Z., Gilbert, S. M., \& Lai, G. (2014). Supplier encroachment under asymmetric information. Management science, 60(2), 449-462.

Lu, L., Gou, Q., Tang, W., \& Zhang, J. (2016). Joint pricing and advertising strategy with reference price effect. International Journal of Production Research, 54(17), 5250-5270.

Ma, S., Li, G., Sethi, S. P., \& Zhao, X. (2019). Advance selling in the presence of market power and risk-averse consumers. Decision Sciences, 50(1), 142-169.

Mailath, G. J., Okuno-Fujiwara, M., \& Postlewaite, A. (1993). Belief-based refinements in signalling games. Journal of Economic Theory, 60(2), 241-276.

Nair, A., \& Narasimhan, R. (2006). Dynamics of competing with quality-and advertising-based goodwill. European Journal of Operational Research, 175(1), 462-474.

Pepper, J. (2012). Russian tide: Building a leadership business in the midst of unprecedented change. Cincinnati, OH: John Pepper.

Riley, Jim. (2013). How Did P\&G Reach the Top in China? Available at https://www.tutor2u.net/business/blog/how-did-pg-reach-the-top-in-china.

Shen, B., Choi T.M., \& Chan, H.L. (2019a). Selling Green First or Not? A Bayesian Analysis with Service Levels and Environmental Impact Considerations in the Big Data Era. Technological Forecasting and Social Change. 144, 412-420.

Shen, B., Choi, T.M., \& Minner, S. (2019b). A Review on Supply Chain Contracting with Information Considerations: Information Updating and Information Asymmetry. International Journal of Production Research. 57(15-16), 4898-4936.

Shen, B., Liu, S., Zhang, T., \& Choi, T.M. (2019c). Optimal Advertising and Pricing for New Green Products in the Circular Economy. Journal of Cleaner Production. 233, 314-327.

Shi, X., Chan, H.L., \& Dong, C. (2020). Value of Bargaining Contract in a Supply Chain System With Sustainability Investment: An Incentive Analysis. IEEE Transactions on Systems, Man, and Cybernetics: Systems. 50(4): 1622-1634.

Sun, X., Tang, W., Chen, J., Li, S., \& Zhang, J. (2019). Manufacturer encroachment with production cost reduction under asymmetric information. Transportation Research Part E: Logistics and Transportation Review, 128, 191-211.

Tian, L., \& Jiang, B. (2017) Comment on "Strategic Information Management Under Leakage in a Supply Chain". Management Science, 63(12), 4258-4260.

UNCTAD (United Nations Conference on Trade and Development). (2019). Key statistics and trends in international trade 2018: International trade rebounds. Available at https://unctad.org/en/PublicationsLibrary/ditctab2019d2_en.pdf.

WTO (World Trade Organization). (2019) World Trade Statistical Review 2019: Highlights of world trade. Available at https://www.wto.org/english/res e/statis_e/wts2019_e/wts2019chapter02_e.pdf.

Xie, J., \& Wei, J. C. (2009). Coordinating advertising and pricing in a manufacturer-retailer 
channel. European Journal of Operational Research, 197(2), 785-791.

Yan, Y., Zhao, R., \& Lan, Y. (2017). Asymmetric retailers with different moving sequences: Group buying vs. individual purchasing. European Journal of Operational Research, 261(3), 903-917.

Zhang, J., Gou, Q., Liang, L., \& Huang, Z. (2013). Supply chain coordination through cooperative advertising with reference price effect. Omega, 41(2), 345-353.

Zhang, J., Li, S., Zhang, S., \& Dai, R. (2019). Manufacturer encroachment with quality decision under asymmetric demand information. European Journal of Operational Research, 273(1), 217-236.

Zhao, D., \& Li, Z. (2018). The impact of manufacturer's encroachment and nonlinear production cost on retailer's information sharing decisions. Annals of Operations Research, 264(1-2), 499-539. 